\title{
Physical and mass transfer properties of electrospun $\varepsilon$-polycaprolactone nanofiber membranes
}

\author{
Artur J. Martins a , Ana I. Bourbon ${ }^{a}$, António A. Vicente ${ }^{a}$, Susana Pinto ${ }^{b}$, \\ José A. Lopes da Silva ${ }^{\mathrm{b}}$, Cristina M.R. Rocha ${ }^{\mathrm{c}, *}$ \\ a CEB-Centre of Biological Engineering, University of Minho, 4710-057 Braga, Portugal \\ b QOPNA, Department of Chemistry, University of Aveiro, Portugal \\ c REQUIMTE, LAQV, Department of Chemical Engineering, Faculty of Engineering, University of Porto, Porto, Portugal
}

\section{A R T I C L E I N F O}

\section{Article history:}

Received 12 August 2014

Received in revised form 17 March 2015

Accepted 18 March 2015

Available online 2 April 2015

\section{Keywords:}

Nanofibers

Electrospinning

Nanoencapsulation

Biopolymer

Fick's diffusion

\begin{abstract}
A B S T R A C T
Determination of material properties and functions is a crucial step toward optimization of fabrication methods as well as the development of electrospun nanofibers for use in, e.g. food engineering applications. This work focused in evaluating physical and mass transfer properties of simple poly $\varepsilon$ caprolactone nanofibers (PCL membrane), and poly $\varepsilon$-caprolactone nanofibers with encapsulated trypsin (E-PCL membrane), in view of their future use in a catalytic filter reactor.

PCL membranes registered high hydrophobicity values, while E-PCL membranes revealed stronger mechanical properties and an increase of mass due to water incorporation. A decrease of average pore size in the range of $30-40 \%$ was observed for E-PCL membranes and an average pore diameter of $1 / 3$ of the size was registered when compared to the PCL membrane; this difference was shown to be significant enough to influence the transport of larger molecules (e.g. bovine serum albumin).

Release experiments of active compounds (lysozyme, bovine serum albumin and lactoferrin) were successfully described by a model which accounts for both Fick and case II transport - the linear superimposition model. Results show that the transport mechanism is influenced by the type of active compound and by membranes' physical properties.
\end{abstract}

(ㄷ) 2015 Elsevier Ltd. All rights reserved.

\section{Introduction}

Peptides are well-known sources of bioactivity and their benefits are reported in a very significant number of scientific works and reports, where their production through affordable, up-scalable processes is still under discussion and development. Trypsin is widely studied and often used as a model enzyme, namely to promote protein hydrolysis for bioactive peptide production. In this case there is the need to separate the products of reaction (peptides with lower size and molecular weight) from the remaining protein and the enzyme itself. This is usually achieved (a) through a filtration/dialysis step, (b) using immobilized trypsin reactors or (c) using an enzyme reactor coupled with ultrafiltration [1,2]. Immobilization of trypsin is often the limiting step due to large losses in enzyme activity as a consequence of (1) the limited area left available for the enzymatic reaction to occur and (2) the immobilization

\footnotetext{
* Corresponding author. Tel.: +35122508 1400; fax: +35122508 1449.

E-mail addresses: avicente@deb.uminho.pt (A.A. Vicente), cmrocha@fe.up.pt (C.M.R. Rocha).
}

step itself [1]. These limitations could be minimized by using immobilization systems with a sufficiently high area-to-volume ratio, such as nanofibers.

Production of nanofibers using electrospinning techniques has been growing in the past years [3]. Electrospinning allows producing polymer nanofibers with specific characteristics (e.g. high porosity and a large surface area per unit mass) [4,5]. This technique is based on the application of an electrical field to a highly conducting polymer solution which will be responsible for the formation of an electrically driven polymer solution jet [3]. Electrospun nanofibers (ENf) produced can easily be functionalized by the addition of nanomaterials in the electrospinning solution or through surface modifications of the scaffold after the spinning process [6]. The significant number of works published on the subject in the past few years and also the increase in published patents [7] reflect the above-mentioned interest, as well as the variety of purposes for this technology. Applications for ENf are as wide as tissue engineering and biomedical devices [8,9], oral drug delivery [10], functional materials (e.g. nano-sensors and fuel cells) $[6,11]$ enzyme (protein) surface immobilization or nanoencapsulation [12]. This methodology allows the production of advanced 
fibrous materials with controlled uniform fiber size for production of low mass filters [3] (e.g. electrospun scaffolds can be used as filtration membranes with antimicrobial functionality [13] or as catalyst surfaces [14]). For many of such demands, a high specific surface area is needed [15] and ENf can be the answer to provide it due to their high porosity and very small pore sizes. ENf also show ability to encapsulate enzymes and the possibility to be functionalized, potentiating their use in simultaneous tasks such as biocatalysis and separation (filtration). Improvement in protein stability through electrospinning polymer processing can resolve further practical issues such as the reduction of required amount of enzymes and the extension of operation lifetime in enzyme reactors [16].

The choice of polymeric materials used in electrospinning processes is not an easy task. Synthetic, biodegradable poly $\varepsilon$-caprolactone is a non-toxic, low-cost, aliphatic biopolyester [17] that has been presented as very useful when applied, e.g. to mimic extracellular matrices [18]. Electrospinning can be used to produce nanofibers from poly $\varepsilon$-caprolactone $[14,19]$. However there are challenges regarding potential applications because of the effects of poly $\varepsilon$-caprolactone hydrophobicity, which can prevent cell adhesion, hinder the mobility of encapsulated bioactivities and also limit the structure's mechanical strength (prerequisite for structural integrity) $[20,21]$.

As a step beyond the state of the art we propose encapsulating trypsin in ENf membranes, which can be subsequently used as a catalytic-filter reactor for simultaneous production and separation of, e.g. bioactive peptides. However, optimizing fabrication methods for enzyme-containing ENf implies starting by characterizing the material (ENf membranes) in terms of its properties and functions. Thus, this study aims at giving this first step by determining the physical and diffusion properties of simple poly $\varepsilon$-caprolactone (PCL) membranes and poly $\varepsilon$-caprolactone nanofibers membranes with encapsulated trypsin (E-PCL). In order to achieve this, three proteins with varying size and isoelectric point $(p I)$, namely bovine serum albumin (BSA), lysozyme (Lys) and lactoferrin (Lact), were used to evaluate the effect of diffusing molecules' size in PCL and EPCL membranes' permeability. Mathematical models were applied to fit permeability experimental data in order to learn more about the structure and behavior of the ENf systems under analysis. These studies were complemented with thermal, structural, mechanical and surface characterization of the ENf systems. Overall, this work sets the bases to use the ENf systems as the main component of a catalytic filter reactor for bioactive peptides production.

\section{Materials and methods}

\subsection{Membrane materials and preparation}

Polycaprolactone (PCL) ( $\mathrm{Mw} \sim 42,000)$, trypsin from porcine pancreas (EC 3.4.21.4), sorbitan monooleate (Span80) and all solvents (analytical grade) were purchased from Sigma-Aldrich Química, S.L.

PCL nanofibers matrices loaded with trypsin were obtained by water/oil emulsion-electrospinning. The oil phase consisted of a PCL solution in chloroform (CF)/dimethylformamide (DMF) and the water phase contained the enzyme in a phosphate buffer, using Span 80 as an emulsifier. Electrospinning conditions and spun solution composition were optimized in order to obtain well-defined fibers free of beads [22]. Electrospun fibrous membranes were prepared using the apparatus previously described [23]. All experiments were carried out in air at room conditions $\left(21 \pm 2{ }^{\circ} \mathrm{C}, 42 \pm 2 \%\right.$ $\mathrm{RH})$.

\subsection{Porosity and pore size}

According to Veleirinho et al., the porosity of the nanofibrous membranes was measured considering the bulk density of PCL as $1.145 \mathrm{~g} / \mathrm{cm}^{3}$ [23]. The pore diameters were measured using a capillary flow porometer (Porometer 3G, Quantachrome Instruments, Boynton Beach, USA). The samples were cut in small circles with $25 \mathrm{~mm}$ of diameter and the thickness was measured using a digital micrometer (model MDC-25S, Mitutoyo Corp., Tokyo, Japan).

\subsection{Membrane structure properties}

\subsubsection{Membrane thickness}

Electrospun membrane thickness was measured in each membrane sample using a digital micrometer (no. 293-561, Mitutoyo, Japan) with \pm 0.001 -mm accuracy. The average thickness of the membranes at five random positions was adopted as the mean thickness of the membrane and was used to calculate swelling, and mechanical values [24].

\subsubsection{Differential scanning calorimetry (DSC) and}

thermogravimetric (TGA) measurements

Differential scanning calorimetry (DSC) measurements were performed with a Shimadzu DSC-50 (Shimadzu Corporation, Kyoto, Japan) calibrated with Indium as standard. Ca. $10 \mathrm{mg}$ of the sample was placed in aluminum DSC pans (Al crimp Pan C.201-52943). According to Cerqueira et al., the measurements were performed between 20 and $250{ }^{\circ} \mathrm{C}$ at a heating rate of $10^{\circ} \mathrm{C} \mathrm{min}-1$ under a nitrogen atmosphere. An empty pans used as reference [25]. Data were treated using TASYS software (Shimadzu Corporation, Kyoto, Japan). Enthalpy was calculated using the area of the peaks between the onset temperature and the end set temperature. The heating scan made possible the determination of the enthalpy of melting $\left(\Delta H_{m}\right)$ and the melting peak $\left(T_{m}\right)$. Thermogravimetric analysis (TGA) was completed with a Shimadzu TGA-50 (Shimadzu Corporation, Kyoto, Japan). Samples were placed in the balance system and heated from 20 to $580^{\circ} \mathrm{C}$ at a heating rate of $10^{\circ} \mathrm{C} \mathrm{min}^{-1}$ under a nitrogen atmosphere.

\subsubsection{Swelling degree (SD)}

The initial mass $\left(m_{i}\right)$ of a circular cut $(d=12 \mathrm{~mm})$ of the mat was quantified after the membrane was stabilized under controlled humidity at $53 \%$ and room temperature; the sample was subsequently immersed in $100 \mathrm{~mL}$ of stirred distilled water at $25^{\circ} \mathrm{C}$ with agitation for $24 \mathrm{~h}$. The wet sample was withdrawn from the bath and carefully blotted between filter paper to remove the excess water from the surface and reweighed $\left(m_{f}\right)$. The swelling degree $(S D)$ was measured in terms of the amount of absorbed water relative to the initial mass (Eq. (1)). The swelling was evaluated for a maximum period of 5 days. These trials were performed in triplicate according to the methodology described by Fajardo et al. [26,27].

$S D=\frac{m_{f}-m_{i}}{m_{i}}$

\subsubsection{Contact angle measurements}

The PCL membrane surface was characterized by contact angle measurements using a tensiometer OCA 15 Plus dynamic (DataPhysics Instruments) using ultra-pure water, formamide and ethylene glycol as standards.

\subsubsection{Mechanical properties}

Mechanical tests were performed at room temperature with the objective of evaluating elongation-at-break (EB) and tensile strength (TS). The tests were performed in an Instron Universal Testing Machine (Model 4500, Instron Corporation, USA) 
following the guidelines of ASTM Standard Method D 882-91 [24]. TS was calculated by dividing the maximum load $(\mathrm{N})$ by the initial cross-sectional area $\left(\mathrm{m}^{2}\right)$ of the specimen. EB was calculated as the ratio of the final and initial length of a specimen, and expressed as a percentage. Samples with a length of $50 \mathrm{~mm}$ and a width of $20 \mathrm{~mm}$ were used, the ends of the rectangular specimens were mounted vertically on mechanical gripping units of the tensile tester. The force and deformation were recorded during extension at $5 \mathrm{~mm} \mathrm{~min}^{-1}$. Measurements of TS and EB were replicated three times for each type of membrane.

\subsubsection{Scanning electron microscopy (SEM)}

The morphology of the membranes was examined using a scanning electron microscope (Nova NanoSEM 200, Netherlands) with an accelerating voltage from 10 to $15 \mathrm{kV}$. Before analyses, all samples were mounted on aluminum stubs using carbon adhesive tape and sputter-coated with gold (thickness of about $10 \mathrm{~nm}$ ).

\subsection{Transport properties}

\subsubsection{Apparatus and solution preparation}

Release measurements were performed in a functional liquid-liquid diffusion system (Fig. 1). This system is based in two acrylic diffusion cells, each one with two distinct compartments: a donor chamber and a receiver chamber, which are separated by the nanofibrous membrane. In order to promote the homogeneity of the liquid phase in both compartments, the receiver chamber has flow recirculation (peristaltic pump set with a selected flow of $10 \mathrm{~mL} / \mathrm{min}$ ) and in the donor chamber a magnetic stirring bar was applied (Fig. 1). Bovine Serum Albumin (BSA), Lysozyme (Lys) and Lactoferrin (Lact) were used as solutes; solutions with concentrations of $1 \mathrm{mg} \mathrm{mL}^{-1}$ were prepared in phosphate buffer of $\mathrm{pH} \sim 7.4$ (BSA and Lys) and $\mathrm{pH} \sim 5.4$ (Lact), sodium azide was added in a $0.05 \%$ to prevent microbial growth and benzamidine was also added to inhibit trypsin activity. The collected samples were analyzed at the collection time by colorimetric protein determination method (Bradford) using ELISA equipment. Samples from the donor chamber were also collected and analyzed to monitor the operational conditions ( $\mathrm{pH}$; protein concentration) during the course of the experimental work. The ENf mats used were: polycaprolactone simple nanofibrous membrane (PCL) and polycaprolactone nanofibrous membrane with encapsulated trypsin (E-PCL).

\subsubsection{Diffusion modeling}

The linear superimposition approach assumes that the observed transport of molecules within the polymer can be described by summing molecules transported due to Brownian motion with molecules transported due to polymer relaxation [28]:

$M_{t}=M_{t, F}+M_{t, R}$

Presented in Eq. (2) above $M(t)$ is the total amount of active compound released $M_{t, F}$ and $M_{t, R}$ are the contributions of the Fickian and relaxation processes, respectively, at time $t$. Mass transport related to Brownian motion in a thin slab membrane immersed in a sufficiently large amount of water, can be described by the solution of Fick's second law for a plane sheet with constant boundary conditions [29]. Hence, compounds release from a polymer slab can be described by:

$$
\begin{aligned}
M_{t}= & M_{\infty, F}\left[1-\frac{8}{\pi^{2}} \sum_{n=0}^{\infty} \frac{1}{(2 n+1)^{2}} \exp \left(-(2 n+1)^{2} k_{F} t\right)\right] \\
& +\sum_{i} M_{\infty, R i}\left[1-\exp \left(-k_{R i} t\right)\right]
\end{aligned}
$$

where $k_{F}$ and $k_{R}$ are Fickian diffusion and relaxation rate constants, respectively.
Table 1

Calorimetric analyses data.

\begin{tabular}{lllll}
\hline Sample & $\begin{array}{l}\text { Melting } \\
\text { temperature } \\
\left({ }^{\circ} \mathrm{C}\right)\end{array}$ & $\begin{array}{l}\text { Onset } \\
\text { temperature } \\
\left({ }^{\circ} \mathrm{C}\right)\end{array}$ & $\begin{array}{l}\text { Endset } \\
\text { temperature } \\
\left({ }^{\circ} \mathrm{C}\right)\end{array}$ & $\Delta H\left(\mathrm{Jg}^{-1}\right)$ \\
\hline$P C L$ & & & & \\
1 & 64.12 & 52.97 & 75.06 & 79.35 \\
2 & 62.83 & 47.36 & 47.00 & 77.85 \\
3 & 65.07 & 52.22 & 76.69 & 79.82 \\
$E-P C L$ & & & & \\
1 & 62.70 & 43.43 & 74.63 & 60.64 \\
2 & 62.11 & 39.44 & 77.91 & 51.31 \\
3 & 64.14 & 49.40 & 76.30 & 65.96 \\
\hline
\end{tabular}

The equations mentioned (Eqs. (2) and (3)) throughout the text, were fitted to data by non-linear regression analysis, using a package of STATISTICA ${ }^{\mathrm{TM}}$ v 7.0 (Statsoft. Inc., USA). The quality of the regressions was evaluated on the basis of the determination coefficient, $R^{2}$, the squared root mean square error, RMSE (i.e. the square root of the sum of the squared residues (SSE) divided by the regression degrees of freedom) and residuals visual inspection for randomness and normality. $R^{2}$ and SSE were obtained directly from the software. The precision of the estimated parameters was evaluated by the Standardized Halved Width (SHW\%), which was defined as the ratio between the $95 \%$ Standard Error (obtained from the software) and the value of the estimate.

\subsubsection{Filtration performance}

The percentage of rejection promoted by the ENf was evaluated during the diffusional trials of the selected compounds. The relationship used to calculate the filtration performance was the following one:

Rejection $\%=\frac{c_{f}-c_{p}}{c_{f}} \times 100$

where $c_{f}$ and $c_{p}$ represent the protein concentration of the feed solution and that of the permeate solution, respectively.

\section{Results and discussion}

\subsection{Differential scanning calorimetry (DSC) test results}

Melting temperatures for the various thermal effects as well as the associated enthalpy changes studied are given in Table 1. The main difference resides in the enthalpy change values that reached higher values for the PCL membranes. Most of the DSC thermograms (Fig. 2) exhibited early endothermic events in the temperature range between 55 and $80^{\circ} \mathrm{C}$. Enthalpy change values in the range of 78 and $80 \mathrm{Jg}^{-1}$ were registered for PCL membrane, while lower values for the E-PCL membrane were observed; this fact may indicate a slight decrease of crystallinity in the E-PCL nanofibrous mats, possibly resulting from the level of entrapment of the enzyme or enzyme aggregates within the polymer fiber, this was in fact decisive for the decrease of fiber freedom, being responsible for increasing enzyme stability and for the decrease of the enthalpy value. Data also confirm the inexistence of water on both nanofiber mats.

\subsection{Thermogravimetric (TGA) measurements}

Thermogravimetric analysis provided information about the weight loss profile for each membrane, also helping to understand the thermal behavior of encapsulated trypsin within the nanofibers. The results show a single mass loss event for all replicates, the weight loss being more effective in the PCL membrane $(10.10 \pm 0.28 \mathrm{mg})$, which is composed only by polycaprolactone 

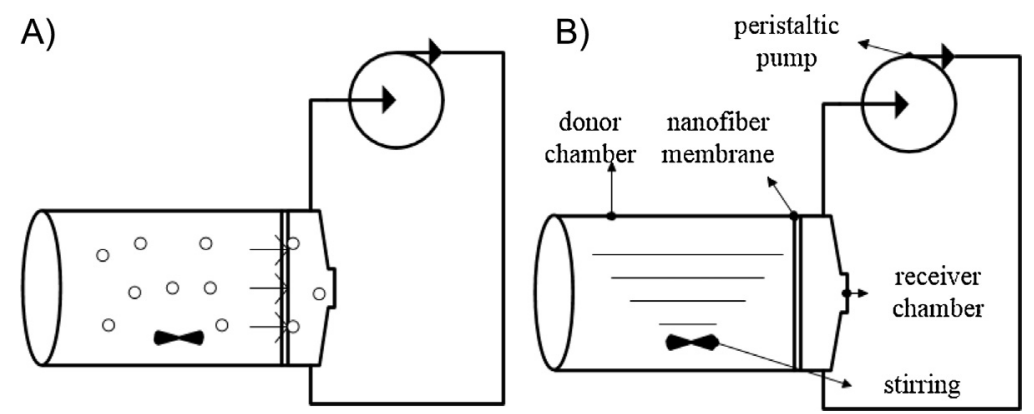

Fig. 1. Schematic diagram of the experimental apparatus for diffusion trials: (A) illustrative scheme and (B) scheme description.

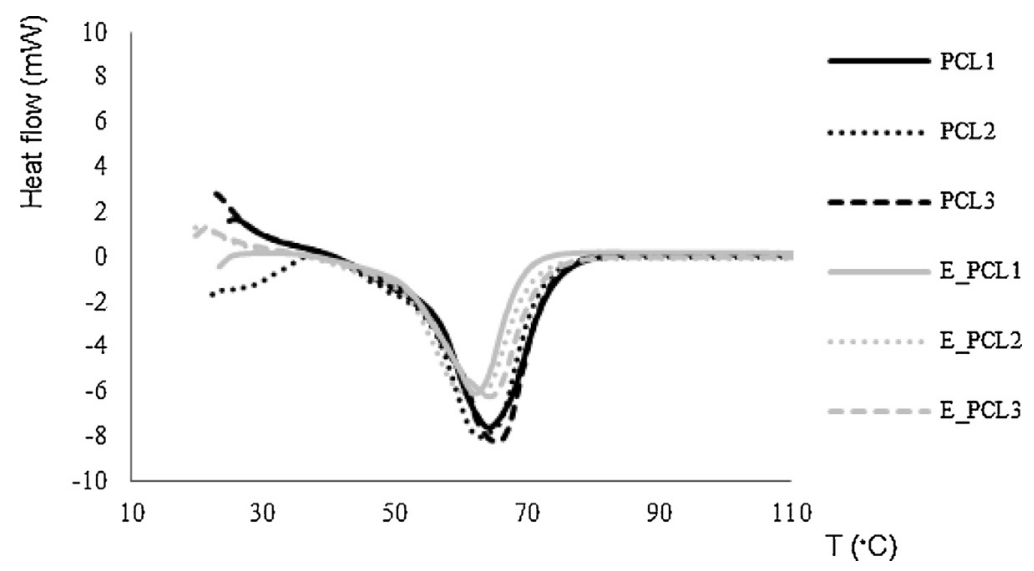

Fig. 2. DSC scans of the six analyzed membranes, obtained at a heating rate of $10^{\circ} \mathrm{C} \mathrm{min}-1$ under nitrogen atmosphere.

nanofibers (Fig. 3). In the case of E-PCL, where the nanofibers serve as encapsulating system for Trypsin the weight loss was $9.35 \pm 0.16 \mathrm{mg}$, corresponding to $80 \%$ of mass loss. This difference, evidenced in Fig. 3, suggests that the entrapment of the enzyme or enzyme aggregates within the polymer fibers will decrease its freedom to move, reducing auto-proteolysis and increasing enzyme stability that can induce a more efficient resistance to degradation.

\subsection{Swelling degree (SD)}

The swelling degree $(S D)$ was evaluated using disks cut from both membranes with average diameter of $12 \mathrm{~mm}$, and with average membrane thickness of $0.089 \mathrm{~mm}$ and $0.138 \mathrm{~mm}$ for PCL and E-PCL membranes, respectively.

All membranes kept their integrity after immersed in water. The general visual appearance of PCL membranes was similar to
Table 2

Swelling degree (SD) values ( $\mathrm{g} \mathrm{H}_{2} \mathrm{O} \mathrm{g}^{-1}$ membrane) for PCL and E-PCL membranes.

\begin{tabular}{lcc}
\hline Sample & Average $S D_{\text {initial }}$ & Average $S D_{\text {final }}$ \\
\hline PCL & $0.12 \pm 0.07$ & $0.07 \pm 0.05$ \\
E-PCL & $2.71 \pm 0.11$ & $0.02 \pm 0.02$ \\
\hline
\end{tabular}

the original scaffold; in contrast the E-PCL membrane displayed a "swollen"-type morphology, as seen in Table 2 . The $S D$ values were in line with the high hydrophobicity of the PCL membranes (as discussed in Section 3.4) in contrast with those of E-PCL; for E-PCL after immersion, $S D$ values were in the range of $2.5-2.9 \mathrm{~g} \mathrm{H}_{2} \mathrm{O} \mathrm{g}^{-1}$ membrane, while for PCL SD values were in the range of $0.02-0.19 \mathrm{~g}$ $\mathrm{H}_{2} \mathrm{O} / \mathrm{g}^{-1}$ membrane. After stabilization and complete drying, E-PCL suffered a reversible process registering values in the same range

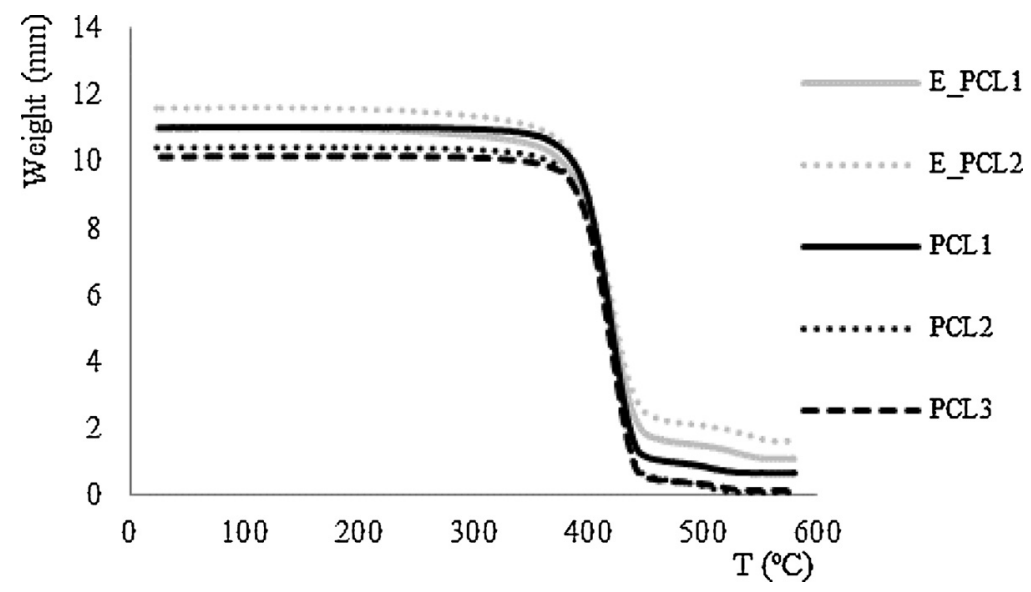

Fig. 3. TGA thermograms. 
Table 3

Mechanical properties of PCL and E-PCL membranes; all values are the average of three measurements \pm standard deviation.

\begin{tabular}{lll}
\hline Sample & $T S(\mathrm{MPa})$ & $E B(\%)$ \\
\hline PCL & $0.24 \pm 0.05$ & $32.12 \pm 1.9$ \\
E-PCL & $1.28 \pm 0.12$ & $33.52 \pm 2.9$ \\
\hline
\end{tabular}

Table 4

Porosity data for PCL and E-PCL.

\begin{tabular}{clll}
\hline Sample & Porosity $(\%)$ & $\begin{array}{l}\text { Average fiber } \\
\text { diameter }(\mathrm{nm})\end{array}$ & $\begin{array}{l}\text { Average pore } \\
\text { diameter }(\mathrm{nm})\end{array}$ \\
\hline PCL & 60.7 & 187 & 2590 \\
E-PCL & 37 & 161 & 760 \\
\hline
\end{tabular}

of the initial ones, however a contraction effect was visible in the dried E-PCL membrane.

\subsection{Contact angle measurement}

The average ultra-pure water contact angle measured for PCL was $134^{\circ}$, revealing a high hydrophobicity of the material. It was not possible to measure contact angles of E-PCL membrane because of their high affinity to all tested liquids. Increased surface energy promoted by the polycaprolactone-trypsin entrapment in the EPCL membrane possibly explains the lower hydrophobicity [30].

\subsection{Mechanical properties}

Table 3 shows the values of mechanical properties of PCL and E-PCL membranes. The values for tensile strength (TS) suffer a significant increase from PCL to E-PCL membranes. This increase of mechanical stiffness can be explained by the higher molecular orientation promoted by the protein encapsulation, which results in strengthened bonding between adjacent PCL molecules. Data from $T S$ experiments show that the decrease of nanofiber diameter observed for E-PCL is associated to an increase of its TS [19]. This increase is not a direct consequence of fiber diameter decrease, but rather a consequence of a higher stacking of nanofiber layers in the structure of E-PCL membranes (in comparison to PCL membrane); this can be confirmed from membrane thickness measurements, as reported above (Section 3.3).

\subsection{Transport properties in the membranes}

Table 4 shows porosity data for PCL and E-PCL membranes. Besides the slight decrease in fiber diameter, a different deposition of the electrospun fibers originated E-PCL membranes with significant lower porosity what will influence their transport properties.

\subsubsection{Transport phenomena of active compounds release}

In order to evaluate the phenomena involved in active compounds transport through PCL and E-PCL nanofiber membranes, molecules with different molecular weights were used: Lys, BSA and Lact with $14 \mathrm{kDa}, 66 \mathrm{kDa}$ and $80 \mathrm{kDa}$, respectively. The migration properties of these compounds through ENf membranes (PCL and E-PCL) were experimentally determined by measuring the $M_{t}$ as a function of time (Fig. 4).

As reported by Gosh [31], Lys is a small, compact molecule and is more likely to behave like a rigid particle with clearly defined charge. On the other hand, BSA being a large flexible molecule is less likely to behave similarly. The lower transmission of BSA through the membrane can be attributed to partial pore blocking. Due to a larger size of the BSA molecule in comparison with Lys, easily pore-blocking phenomena can occur during molecular transport across the membrane, resulting in a larger rejection percentage.
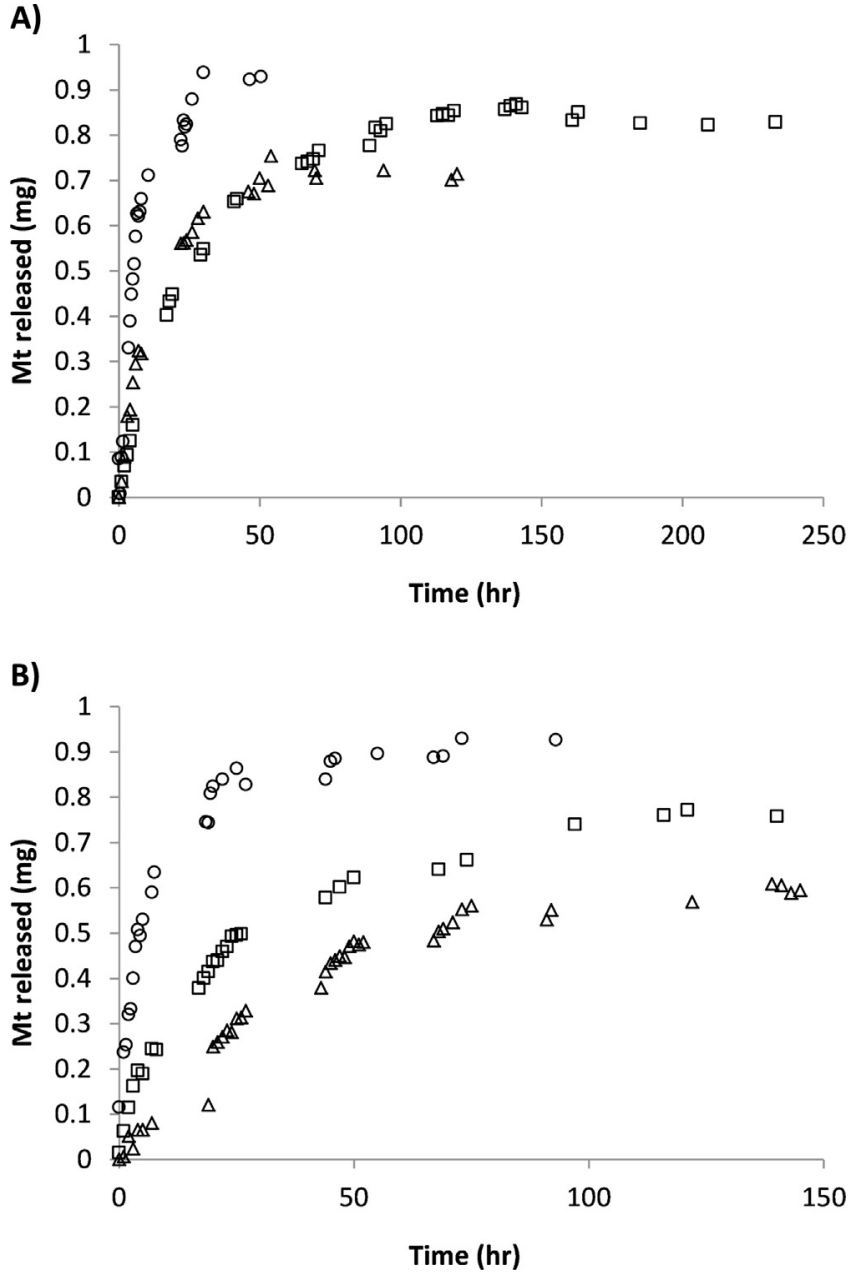

Fig. 4. Active compounds release profiles at $25^{\circ} \mathrm{C}$ from (A) PCL membranes and (B) E-PCL membranes ( $\bigcirc$ - Lys, $\square-$ BSA and $\Delta$ - Lact).

This is clearly seen in Fig. 4. Also, from Fig. 4 it can be seen that compounds release through ENf membranes is characterized by two different phases. Initially a rapid release of active compounds is observed, followed by a period during which the release profile becomes constant indicating a sustained release ("lag time"). The initial quick release can be due to volume expansion of polymer when immersed in liquid media [32]. In aqueous liquid media, depending on the nature of polymers (hydrophilic or hydrophobic), the membranes start to hydrate causing relaxation of the polymer chain. In the present case, it was observed that PCL membranes (Fig. 4A) revealed a more hydrophobic behavior (which is consistent with the other results described herein) and thus shows a more pronounced release in a short period of time when compared with E-PCL membranes (Fig. 4B). This effect clearly affects the initial migration of active compounds from ENf membranes and consequently the amount of active compounds released.

In order to assess the transport properties (i.e. diffusion and the relaxation processes) of the PCL and E-PCL membranes, a linear superimposition model (Eq. (2)) [28] was fitted to the experimental data. Table 5 shows the parameters of the model after that fitting procedure. The total mass released via relaxation transport $\left(M_{R}\right)$ is higher than the total mass released via Fick's transport $\left(M_{F}\right)$ for both membranes (PCL and E-PCL). These results suggest that the compounds release from ENf membranes is driven mostly by the swelling ability of the polymer, i.e. by the configuration of the system at any given time related to the configuration of the maximum swelled matrix (i.e. at equilibrium) [28]. However, it is 
Table 5

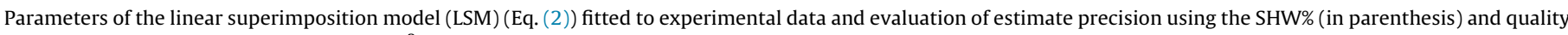
of the regression on the basis of RMSE and $R^{2}$.

\begin{tabular}{|c|c|c|c|c|c|c|c|c|c|}
\hline \multirow{2}{*}{$\begin{array}{l}\text { Molecular } \\
\text { weight (KDa) }\end{array}$} & \multirow{2}{*}{$\begin{array}{l}\text { Active } \\
\text { compound }\end{array}$} & \multirow[t]{2}{*}{ Membrane } & \multicolumn{7}{|c|}{ LSM - one relaxation $(i=1)$} \\
\hline & & & $M_{F}$ & $k_{F}$ & $M_{R}$ & $k_{R}$ & $M_{R} / M_{F}$ & $R^{2}$ adj & RSME \\
\hline \multirow{2}{*}{14} & \multirow{2}{*}{ Lys } & PCL & $\begin{array}{l}8.34 \times 10^{-3} \\
(85.61 \%)\end{array}$ & $\begin{array}{l}1.35 \times 10^{-1} \\
(99.16 \%)\end{array}$ & $\begin{array}{l}8.45 \times 10^{-1} \\
(67.26 \%)\end{array}$ & $\begin{array}{l}1.61 \times 10^{-1} \\
(60.46 \%)\end{array}$ & 101.32 & 0.97 & $4.80 \times 10^{-2}$ \\
\hline & & E-PCL & $\begin{array}{l}1.14 \times 10^{-2} \\
(27.81 \%)\end{array}$ & $\begin{array}{l}1.70 \times 10^{-1} \\
(33.91 \%)\end{array}$ & $\begin{array}{l}3.25 \times 10^{-1} \\
(39.51 \%)\end{array}$ & $\begin{array}{l}5.40 \times 10^{-2} \\
(39.99 \%)\end{array}$ & 28.51 & 0.99 & $1.51 \times 10^{-2}$ \\
\hline \multirow{2}{*}{66} & \multirow{2}{*}{ BSA } & PCL & $\begin{array}{l}7.02 \times 10^{-2} \\
(64.74 \%)\end{array}$ & $\begin{array}{l}1.97 \times 10^{-1} \\
(63.65 \%)\end{array}$ & $\begin{array}{l}7.80 \times 10^{-1} \\
(13.79 \%)\end{array}$ & $\begin{array}{l}3.26 \times 10^{-2} \\
(12.02 \%)\end{array}$ & 11.11 & 0.99 & $8.49 \times 10^{-3}$ \\
\hline & & E-PCL & $\begin{array}{l}2.41 \times 10^{-1} \\
(34.84 \%)\end{array}$ & $\begin{array}{l}1.30 \times 10^{-1} \\
(45.02 \%)\end{array}$ & $\begin{array}{l}5.43 \times 10^{-1} \\
(16.59 \%)\end{array}$ & $\begin{array}{l}2.36 \times 10^{-2} \\
(25.24 \%)\end{array}$ & 2.25 & 0.99 & $7.68 \times 10^{-3}$ \\
\hline \multirow{2}{*}{80} & \multirow{2}{*}{ Lact } & PCL & $\begin{array}{l}8.23 \times 10^{-3} \\
(62.72 \%)\end{array}$ & $\begin{array}{l}2.59 \times 10^{-2} \\
(76.79 \%)\end{array}$ & $\begin{array}{l}6.39 \times 10^{-1} \\
(20.69 \%)\end{array}$ & $\begin{array}{l}7.89 \times 10^{-2} \\
(10.10 \%)\end{array}$ & 77.64 & 0.99 & $1.02 \times 10^{-2}$ \\
\hline & & E-PCL & $\begin{array}{l}3.66 \times 10^{-2} \\
(68.98 \%)\end{array}$ & $\begin{array}{l}2.90 \times 10^{-2} \\
(99.89 \%)\end{array}$ & $\begin{array}{l}5.72 \times 10^{-1} \\
(13.96 \%)\end{array}$ & $\begin{array}{l}2.90 \times 10^{-2} \\
(97.88 \%)\end{array}$ & 15.63 & 0.99 & $8.02 \times 10^{-3}$ \\
\hline
\end{tabular}

possible verify that the $M_{R} / M_{F}$, is always higher for E-PCL than for PCL membranes.

For PCL membranes the molecular weight did not affect the total mass released via Fick's transport $\left(M_{F}\right)$, but this parameter decreased for increasing molecular weight compounds' transport in the case of E-PCL. This behavior can be explained by the lower hydrophobicity of E-PCL membrane and the lower crystallinity (results mentioned above). As for the relaxation component of transport, the mass released $\left(M_{R}\right)$ is higher for PCL membrane and is not affected by the molecular weight of active compounds. However, for E-PCL the increase of active compounds molecular weight increased the $M_{R}$ released. These results may indicate that compounds are interacting with the membranes in a totally different way. Results mentioned above showed that the reduction of pore size and crystallinity resultant of trypsin encapsulation could be determinant for the rate of compound migration through the membrane, hence prompting partial clogging with the resultant of compound association with the nanofibers.

Fickian rate of diffusion, $k_{F}$, decreased with increasing compounds' molecular weight in E-PCL membranes while in PCL membranes this parameter is not affected by molecular weight.

Finally, the relaxation rate of diffusion, $k_{R}$ was similar for the different active compounds in both membranes. This should be expected since this is a property of the polymer and not of the molecule diffusing through polymer $[33,34]$.

From a mathematical point of view, a good agreement between the model-generated and experimental values was found for all tested conditions, suggesting that this model is able to describe the experimental data and, hence, the physical mechanism of the transport phenomena involved here. Fig. 5 shows an example of the fitting of Eq. (2) to the experimental data of active compounds release kinetics (in this case, of BSA from PCL membrane (Fig. 5A) and of Lys from E-PCL membrane (Fig. 5B)).

\subsection{Filtration performance}

Regarding filtration performance of the ENf membranes, data in Table 6 show that in general PCL membranes revealed a more efficient transport of molecules from the feed phase to the

Table 6

Rejection percentage of active compounds $\left(1 \mathrm{mg} \mathrm{mL}^{-1}\right.$ at $\left.\mathrm{pH} 7.4\right)$ obtained in the diffusional trials with simple PCL and E-PCL membranes.

\begin{tabular}{llrl}
\hline Sample & Lys & \multicolumn{1}{c}{ BSA } & Lact \\
\hline PCL & $0.0 \%$ & $7.8 \%$ & $22.5 \%$ \\
E-PCL & $1.4 \%$ & $13.9 \%$ & $38.9 \%$ \\
\hline
\end{tabular}

permeate phase than their E-PCL counterparts. The migration of BSA was more effective with the PCL membrane (the value of rejection with E-PCL was almost doubled). The migration of Lys was virtually complete (only a low percentage of rejection was registered with E-PCL). The filtration performance allows us to understand that E-PCL revealed more retention of solute in comparison with PCL. Even with Lys, which has a smaller size than BSA, the behavior was similar. The porosity of the membranes acts as a main factor when it comes to protein migration through the scaffolds. The larger average porosity of PCL, shown in Table 4, was
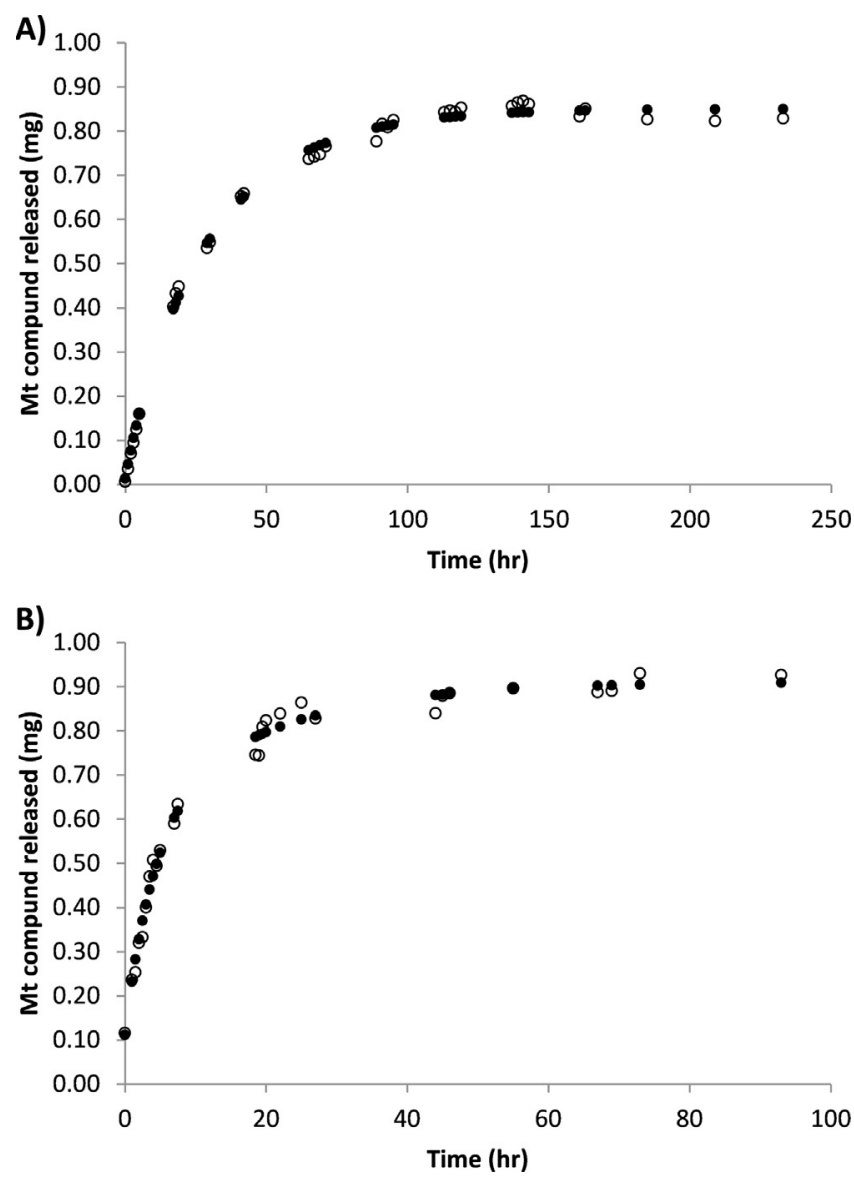

Fig. 5. Fitting of Eq. (2) to: (A) BSA controlled release experimental data from PCL membrane and (B) Lys controlled release experimental data from E-PCL membrane (experimental results $(\bigcirc)$; model-generated values $(\bullet)$ ). 

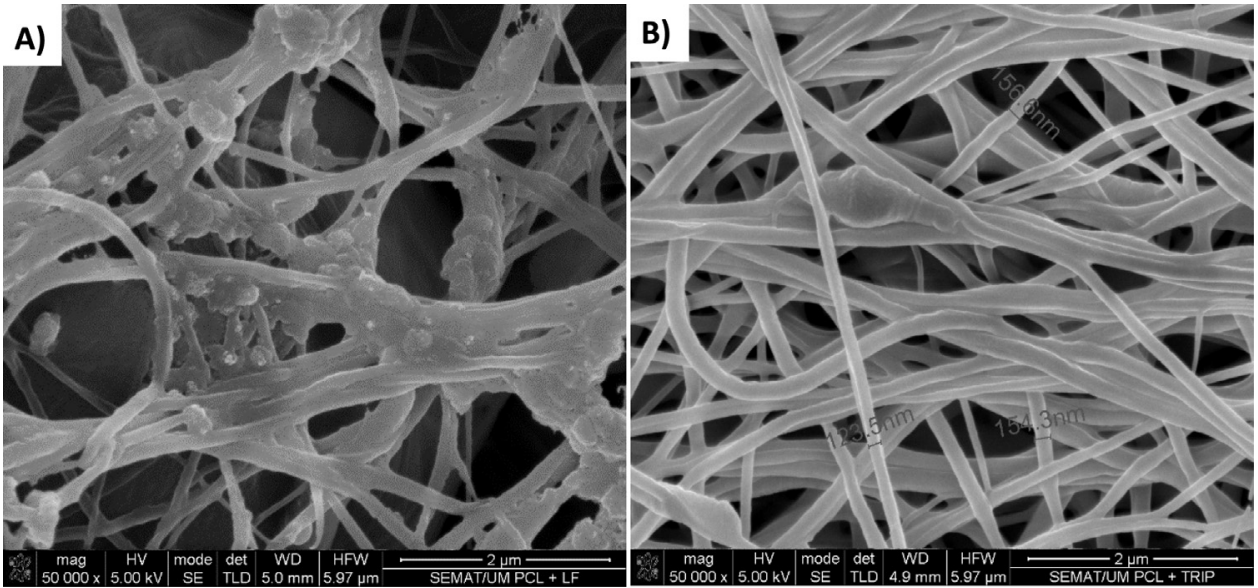

Fig. 6. SEM micrographs of (A) PCL membrane with Lact fouling after diffusion experiments and (B) E-PCL membrane with reference to fiber sizes.

the main responsible factor for the lower percentage of protein rejection (retention) and the reverse effect is observed in E-PCL. The molecular weight of the proteins was also responsible for the differences of retention.

\subsection{Membrane morphology}

Scanning electron microscopy allows visualizing the morphological structure of the membranes, mainly the size and the porosity of the membrane matrix (Fig. 6A and B). It is also possible to observe the retention of compounds after the release experiments. In this case, Lact release from PCL membrane was shown as an example (Fig. 6A). In Fig. 6B, data regarding the E-PCL nanofiber diameter are presented. These images corroborate the results described above, mainly the retention of compounds at the membrane's surface after the diffusional tests; the difference in the porosity of both membranes and the similar average fiber sizes is also noticeable.

\section{Conclusions}

It was demonstrated that nanoencapsulation of trypsin in PCL ENf produced a different scaffold in terms of mechanical, surface and transport properties. These E-PCL membranes revealed a much different behavior in the presence of an aqueous phase, a higher affinity to water, as well as a better mechanical resistance. E-PCL membranes also revealed an average weight loss of $10 \%$ lower than PCL membranes and a lower melting enthalpy change value, in spite of both melting peaks being in the same range. The significant difference in average pore diameter was an important factor in terms of solute permeability, making this E-PCL membrane a suitable filter for specific high molecular weight particles.

\section{Acknowledgments}

The present study was developed under the scope of the NanoBioCats project (PTDC/CTM-POL/112289/2009), funded by the Portuguese Science and Technology Foundation (Fundação para a Ciência e a Tecnologia - FCT). This work was also supported by the COMPETE program (funded by the European Union fund, FEDER under the framework of QREN (Programa Operacional Regional do Norte (ON.2 - O Novo Norte; FEDER))) through projects NORTE-070124-FEDER-000028 and NORTE-07-0124-FEDER-000069. Also, the authors thank Strategic Projects PEst-OE/EQB/LA0023/2013, PEst-C/EQB/LA0006/2013 - FCOMP-01-0124-FEDER-37285 and PEst-C/QUI/UI0062/2013 - FCOMP-01-0124-FEDER-037296. The author Ana Isabel Bourbon is recipient of a fellowship from the
Fundação para a Ciência e Tecnologia (FCT, Portugal) through grant SFRH/BD/73178/2010.

\section{References}

[1] Rocha C, Gonçalves MP, Teixeira JA. Immobilization of trypsin on spent grains for whey protein hydrolysis. Process Biochem 2011;46:505-11.

[2] Chen SX, Swaisgood HE, Foegeding EA. Gelation of beta-lactoglobulin treated with limited proteolysis by immobilized trypsin. J Agric Food Chem 1994;42:234-9.

[3] Yun KM, Hogan CJ, Matsubayashi Y, Kawabe M, Iskandar F, Okuyama K. Nanoparticle filtration by electrospun polymer fibers. Chem Eng Sci 2007;62:4751-9.

[4] Frenot A, Chronakis IS. Polymer nanofibers assembled by electrospinning. Curr Opin Colloid Interface Sci 2003;8:64-75.

[5] Veleirinho B, Lopes-da-Silva JA. Application of electrospun poly(ethylene terephthalate) nanofiber mat to apple juice clarification. Process Biochem 2009;44:353-6.

[6] Matlock-Colangelo L, Baeumner AJ. Recent progress in the design of nanofiberbased biosensing devices. Lab Chip 2012;12:2612-20.

[7] Persano L, Camposeo A, Tekmen C, Pisignano D. Industrial upscaling of electrospinning and applications of polymer nanofibers: a review. Macromol Mater Eng 2013:298:504-20.

[8] Ruckh T, Carroll D, Weaver J, Popat K. Mineralization content alters osteogenic responses of bone marrow stromal cells on hydroxyapatite/polycaprolactone composite nanofiber scaffolds. J Funct Biomater 2012;3:776-98.

[9] Liu S, Liu S, Liu X, Zhao J, Cui W, Fan C. Antibacterial antiadhesion membranes from silver-nanoparticle-doped electrospun poly(L-lactide) nanofibers. J Appl Polym Sci 2013;129:3459-65.

[10] Ignatious F, Sun L, Lee CP, Baldoni J. Electrospun nanofibers in oral drug delivery. Pharm Res 2010;27:576-88.

[11] Agarwal S, Greiner A, Wendorff JH. Functional materials by electrospinning of polymers. Prog Polym Sci 2013;38:963-91.

[12] Tran DN, Balkus KJ. Enzyme immobilization via electrospinning. Top Catal 2012;55:1057-69.

[13] Lala NL, Ramaseshan R, Bojun L, Sundarrajan S, Barhate RS, Ying-Jun L, et al. Fabrication of nanofibers with antimicrobial functionality used as filters: protection against bacterial contaminants. Biotechnol Bioeng 2007;97:1357-65.

[14] Fang J, Niu H, Lin T, Wang X. Applications of electrospun nanofibers. Chin Sci Bull 2008;53:2265-86.

[15] Ramaseshan R, Sundarrajan S, Jose R, Ramakrishna S. Nanostructured ceramics by electrospinning. J Appl Phys 2007;102:111101.

[16] Kim J, Grate JW, Wang P. Nanostructures for enzyme stabilization. Chem Eng Sci 2006;61:1017-26.

[17] He L, Chen J, Farson DF, Lannutti JJ, Rokhlin SI. Wettability modification of electrospun poly( $\varepsilon$-caprolactone) fibers by femtosecond laser irradiation in different gas atmospheres. Appl Surf Sci 2011;257:3547-53.

[18] Bajgai MP, Aryal S, Bhattarai SR, Bahadur KCR, Kim K-W, Kim HY. Poly( $\varepsilon$-caprolactone) grafted dextran biodegradable electrospun matrix: a novel scaffold for tissue engineering. J Appl Polym Sci 2008;108: 1447-54.

[19] Baji A, Mai Y-W, Wong S-C, Abtahi M, Chen P. Electrospinning of polymer nanofibers: effects on oriented morphology, structures and tensile properties. Compos Sci Technol 2010;70:703-18.

[20] Zoppe JO, Peresin MS, Habibi Y, Venditti RA, Rojas OJ. Reinforcing poly(epsiloncaprolactone) nanofibers with cellulose nanocrystals. ACS Appl Mater Interfaces 2009;1:1996-2004. 
[21] Ghasemi-Mobarakeh L, Prabhakaran MP, Morshed M, Nasr-Esfahani MH, Ramakrishna S. Electrospun poly(epsilon-caprolactone)/gelatin nanofibrous scaffolds for nerve tissue engineering. Biomaterials 2008;29:4532-9.

[22] Pinto S, Saraiva JA, Lopes da Silva JA. Immobilization of trypsin in electrospun polycaprolactone nanofibers. In: BioSpain 2012 6th international meeting on biotechnology. 2012.

[23] Veleirinho B, Rei MF, Lopes-Da-Silva JA. Solvent and concentration effects on the properties of electrospun poly(ethylene terephthalate) nanofiber mats. J Polym Sci B: Polym Phys 2008;46:460-71.

[24] Martins JT, Bourbon AI, Pinheiro AC, Souza BWS, Cerqueira MA, Vicente AA. Biocomposite films based on к-carrageenan/locust bean gum blends and clays: physical and antimicrobial properties. Food Bioprocess Technol 2012;6:2081-92.

[25] Cerqueira MA, Souza BWS, Teixeira JA, Vicente AA. Effect of glycerol and corn oil on physicochemical properties of polysaccharide films - a comparative study. Food Hydrocoll 2012;27:175-84.

[26] Fajardo P, Martins JT, Fuciños C, Pastrana L, Teixeira JA, Vicente AA. Evaluation of a chitosan-based edible film as carrier of natamycin to improve the storability of Saloio cheese. J Food Eng 2010;101:349-56.
[27] da Silva M, Bierhalz A, Kieckbusch T. Physical-chemical properties of alginate/chitosan composite films containing natamycin as antimicrobial agent. In: Proceedings of the 11th international congress on engineering and food (ICEF11). 2011. p. 6

[28] Berens AR, Hopfenberg HB. Diffusion and relaxation in glassy polymer powders. 2. Separation of diffusion and relaxation parameters. Polymer 1978;19:489-96.

[29] Crank J. The mathematics of diffusion. Oxford: Clarendon Press: 1975.

[30] Kim G, Min T, Park SA, Kim WD, Koh YH. Fabrication of a biocomposite reinforced with hydrophilic eggshell proteins. Biomed Mater 2007;2:250-6.

[31] Ghosh R. Fractionation of BSA and lysozyme using ultrafiltration: effect of pH and membrane pretreatment. J Membr Sci 1998;139:17-28.

[32] Beirão-da-Costa S, Duarte C, Bourbon AI, Pinheiro AC, Januário MIN, Vicente $\mathrm{AA}$, et al. Inulin potential for encapsulation and controlled delivery of Oregano essential oil. Food Hydrocoll 2013;33:199-206.

[33] Pinheiro AC, Bourbon AI, Vicente AA, Quintas MAC. Transport mechanism of macromolecules on hydrophilic bio-polymeric matrices - diffusion of proteinbased compounds from chitosan films. J Food Eng 2013;116:633-8.

[34] Vrentas JS, Jarzebski CM, Duda JL. A Deborah number for diffusion in polymersolvent systems. AIChE J 1975;21:894-901. 